\title{
VARIANCE AND DISSENT
}

Editor's Note: All components of this Variance and Dissent trio had been completed and prepared for publication when we learned, with sadness, that Dr. Chalmers had died, at age 78, on December 27, 1995. His Dissent here is stated with his characteristic vigor. It was also present in his previous publication [1995;48:45-57] in the Journal of Clinical Epidemiology: a spirited advocacy of meta-analysis, which he helped inaugurate and develop as a new methodologic procedure in medical research. Chalmers will be remembered and honored as an early and productive pioneer in clinical epidemiology. In leadership roles at the U.S. Veterans Administration and National Institutes of Health, his intellectual and administrative support of randomized trials helped lead to their establishment as a prime source of therapeutic evidence. He and I did not always agree about the many ideas fermenting in a new field, but we happily made common cause in collaborating to advance the ferment, and to arrange its expression through media such as the Sydenham Society. I shall personally miss the fun and challenge of his provocative stimulation; and the field of clinical epidemiology is indebted for his many contributions.

\section{Presentation}

\section{Vitamin C, the Placebo Effect, and the Common Cold: A Case Study of How Preconceptions Influence the Analysis of Results}

\author{
Harri Hemilä* \\ DEPARTMENT OF PUBLIC HEALTH, UNIVERSITY OF HELSINKI, HELSINKI, FINLAND
}

\begin{abstract}
A large number of placebo-controlled studies have shown that vitamin $\mathrm{C}$ supplementation alleviates the symptoms of the common cold, but widespread skepticism that vitamin $C$ could have any significant effect remains. One of the most influential common cold studies, published in 1975, was carried out by Thomas Karlowski et al. at the National Institutes of Health. Their placebo consisted of lactose, which can easily be distinguished from ascorbic acid by taste. Karlowski et al. found a 17\% decrease in the duration of cold episodes in the group administered vitamin C (6 g/day); however, they suggested that the decrease was entirely due to the placebo effect. In this article it will be shown that the placebo effect is not a valid explanation for the results of the Karlowski study, as it is inconsistent with their results. This is an important conclusion for two reasons. First, the placebo explanation becomes even more unreasonable as regards the reported benefits found in several other studies with valid placebo tablets. Second, as the results from the Karlowski study are not due to the placebo effect, their results can be used to assess the quantitative effects of vitamin $\mathrm{C}$ supplementation. The most important conclusions from Karlowski's study are that therapeutic vitamin $\mathrm{C}$ supplementation during a common cold episode appears to be as effective as regular supplementation, and that there appears to be linear dose dependency at least up to $6 \mathrm{~g} / \mathrm{day}$. These findings suggest that large therapeutic vitamin $\mathrm{C}$ doses might alleviate the symptoms of the common cold substantially. J CLIN EPIDEMIOL 49;10:1079-1084, 1996.
\end{abstract}

KEY WORDS. Vitamin C, ascorbic acid, placebo effect, common cold, viral infections

\section{INTRODUCTION}

Vitamin $\mathrm{C}$ supplementation has frequently been suggested for the treatment of the common cold [1-11], which is among the most frequent causes of visits to physicians and of absenteeism [12]. Gram doses of vitamin $\mathrm{C}$ per day have been found to be essentially harmless even with long-term usage $[13,14]$. Therefore it appears worthwhile to examine thoroughly whether vitamin $\mathrm{C}$ supplementation does have beneficial effects during common cold episodes.

In 1975 Thomas Karlowski et al. published a vitamin C-common cold study [15] that received widespread attention for two particular reasons. First, as the study was carried out at the National Institutes of Health (NIH) and the subjects of the study were employees of the

Address reprint requests to: Harri Hemilä,* Department of Public Health, P.O. Box 41, University of Helsinki, Helsinki, FIN-00014 Finland. Accepted for publication 4 January 1996.
$\mathrm{NIH}$, the social background gave the study considerable influence. Second, the study was published in the Journal of the American Medical Association (JAMA), a respected journal with a very wide circulation.

However, technically the Karlowski study is not among the best, since their placebo consisted of lactose, which is sweet, whereas they used ascorbic acid in the vitamin $\mathrm{C}$ tablets, so that it is possible that some of the subjects identified the tablets by taste. In fact, it was concluded by the authors that the results were entirely due to the placebo effect: "the effects demonstrated might be explained equally well by a break in the double blind" [15], and this was also forcefully emphasized in a concurrent review [16] written by Thomas Chalmers, one of the members of the Karlowski team. The "placebo explanation" of Karlowski's results has been reiterated in a major textbook on infectious diseases [12] and in several other commentaries on the vitamin C-common cold relationship [17-19]. The Kar- 
TABLE 1. Results of the Karlowski study: Duration of cold episodes (in days) in four treatment groups

\begin{tabular}{|c|c|c|c|}
\hline \multirow[b]{2}{*}{$\begin{array}{l}\text { Prophylactic } \\
\text { tablets (each day) }\end{array}$} & \multicolumn{2}{|c|}{$\begin{array}{c}\text { Therapeutic tablets } \\
\text { (5 days during an } \\
\text { episode) }\end{array}$} & \multirow[b]{2}{*}{ Difference (days) } \\
\hline & Placebo & $\begin{array}{l}\text { Vitamin C } \\
\text { (3 g/day) }\end{array}$ & \\
\hline \multirow[t]{2}{*}{ Placebo } & $\begin{array}{c}7.14 \underset{(65)}{ \pm 0.46} \\
\neq 0\end{array}$ & $\begin{array}{c}6.46 \pm 0.39 \\
(56) \\
\# 1\end{array}$ & $-0.68 \pm 0.61$ \\
\hline & & & $\begin{array}{c}\text { Mean: }-0.735 \pm 0.44 t \\
(t=1.65, p=0.10)\end{array}$ \\
\hline $\begin{array}{l}\text { Vitamin C } \\
(3 \mathrm{~g} / \text { day })\end{array}$ & $\begin{array}{c}6.71 \underset{(52)}{ \pm 0.53} \\
\# 2\end{array}$ & $\begin{array}{c}5.92 \pm 0.40 \\
(76) \\
* 3\end{array}$ & $-0.79 \pm 0.65$ \\
\hline \multirow[t]{2}{*}{ Difference (days) } & -0.43 & -0.54 & $\begin{array}{c}-1.22 \pm 0.61 \\
(t=2.01, p=0.05)\end{array}$ \\
\hline & \multicolumn{2}{|c|}{ Mean: -0.485} & \\
\hline
\end{tabular}

${ }^{a}$ Prophylactic tablets were administered each day and therapeutic tablets were administered for 5 days during cold episodes. The outcome is the mean duration of episodes in days ( \pm standard error); data are from $[15,16,25]$. The number of colds in each group is shown in parentheses and the numbers used to designate the study groups [15] are marked below the mean duration of cold episodes (\#). The differences and the statistical significance of the differences were calculated by the present author, since Karlowski et al. did not report the results from their statistical analysis, as they assumed that the differences between groups were purely due to the placebo effect [15]. The $p$ values are two-tailed.

lowski study even led to a suggestion that the placebo effect could be a general explanation for benefits observed in other common cold studies [16]. The latter proposal is simply unfounded, since in a large number of studies it has been explicitly confirmed that the placebo and vitamin $C$ tablets were indistinguishable [20-24].

Although the placebo was improperly selected in the Karlowski study, there are no other grave shortcomings in the study. Moreover, the study contains certain important features. The Karlowski study was reasonably large, having 190 subjects with a total of 249 cold episodes, and the vitamin $\mathrm{C}$ doses used were among the highest so far (3-6 g/day). Biologically, the most important features of the study are the direct comparison of the therapeutic and prophylactic methods of supplementation and the comparison of two different dosages ( 3 and $6 \mathrm{~g} /$ day) in the same study. Therefore, if the "placebo explanation" favored by the authors $[15,16]$ can be confidently rejected, the results of the Karlowski study can be used to compare therapeutic versus regular supplementation and to analyze the dose dependency up to $6 \mathrm{~g} /$ day.

\section{INTERPRETATION OF KARLOWSKI'S RESULTS The Basis of the "Placebo Explanation"}

The Karlowski study [15] lasted for 9 months and there were four treatment groups in the study (Table 1). Each subject received two kinds of tablets: prophylactic (each day) and therapeutic (5 days during a cold). Ascorbic acid ( $3 \mathrm{~g} /$ day) was used in the active tablets and lactose was used in the placebo tablets, a different combination being administered to each of the four groups. The mean duration of cold episodes in each of the study groups is shown in Table 1.

After the Karlowski study was completed the subjects were asked in a questionnaire to guess which tablets they were given [15]. In the case of prophylactic tablets there was very strong bias in favor
TABLE 2. Prophylactic tablets: Guessing the treatment

\begin{tabular}{|c|c|c|c|c|}
\hline \multirow[b]{2}{*}{ Actual drug } & \multicolumn{2}{|c|}{ Answer } & \multirow{2}{*}{$\begin{array}{l}\text { Did not } \\
\text { guess }\end{array}$} & \multirow{2}{*}{$\begin{array}{c}\text { Total } \\
\text { subjects }\end{array}$} \\
\hline & Placebo & Vitamin C & & \\
\hline \multirow{3}{*}{$\begin{array}{l}\text { Placebo } \\
\text { Vitamin C }\end{array}$} & & $11(12 \%)^{\pi}$ & \multirow{3}{*}{$\begin{array}{l}39 \\
49\end{array}$} & \multirow{3}{*}{$\begin{array}{r}89 \\
101\end{array}$} \\
\hline & $12(12 \%)^{4}$ & 40 & & \\
\hline & \multicolumn{2}{|c|}{$x^{2}=28.6^{h} p<10^{-6}$} & & \\
\hline
\end{tabular}

Subjects divided into groups on the basis of "guessing" and "knowing";

\begin{tabular}{llllll} 
& \multicolumn{2}{c}{ "Guessing" } & & \multicolumn{2}{c}{ "Knowing" } \\
\cline { 2 - 3 } \cline { 5 - 6 } Actual drug & Placebo & Vitamin C & & Placebo & Vitamin C \\
\hline Placebo & $11^{c}$ & 11 & & 28 & $-\overline{28}$ \\
Vitanin C & 12 & $12^{c}$ & & - & \\
\hline
\end{tabular}

${ }^{a}$ Percentage of subjects receiving the actual drug

${ }^{b} \chi^{2}$ test with Yates' correction. Karlowski et al. [15] obtained the same $\chi^{2}$ value (28.6), indicating that they also used Yates' correction in analyzing the answers as to the prophylactic tablets. However, in the case of the therapeutic tablets Karlowski et al. did not use Yates' correction (cf. Table 3).

${ }^{c}$ Correct guesses have been estimated from the number of wrong answers.

of correct answers (Table 2; $p<10^{-6}$ ). In contrast, there was barely any evidence of bias in the case of therapeutic tablets (Table 3; $p=0.27)$.

Karlowski et al. assumed that all subjects giving a correct answer genuinely identified the treatment, without taking into consideration that there also were pure guesses among the correct answers. Thus, Karlowski et al. assumed that $79(=40+39)$ subjects "knew" whether they were given vitamin $\mathrm{C}$ or placebo as prophylactic tablets (Table 2; cf Table 4 in [15]). However, this is most probably an erroneous assumption. In the case of the prophylactic tablets, $12 \%$ of subjects gave the wrong answer both for placebo and vitamin $\mathrm{C}$ (Table 2). Assuming that the subjects gave a correct answer purely as a guess with a similar frequency, we may estimate that $56(=28$ $+28)$ subjects "really knew" their prophylactic tablets. Thus, of all subjects about 29\% (56/190) genuinely recognized the prophylactic tablets at the end of the study.

For the therapeutic tablets, there was no substantial evidence that the distribution of answers was not due to pure chance (Table 3 ). However, assuming that there is actual but slight bias, we may use the number of wrong answers $(16 \%)$ to estimate the number of subjects genuinely recognizing their tablets. We may estimate that 11 $(=9+2)$ subjects "really knew" the therapeutic tablets, which is considerably lower than the estimate derived on the basis of Karlowski's rationalization $(32=20+12)$. Thus, of all subjects receiving therapeutic tablets about $8 \%(11 / 132)$ genuinely recognized the type of therapeutic tablet at the end of the study.

Obviously, it is impossible to know purely on the basis of a correct answer which of the subjects genuinely knew and which simply guessed the correct answer. There appears to be no sound basis for treating the two groups as one homogeneous group. Nevertheless, Karlowski et al. used "correct answer" as a surrogate for "knowing" and designated the subjects giving correct answers as "unblinded" [15]. There were dramatic differences between the vitamin $C$ and placebo groups in the "unblinded" subjects (Table 4), far greater than in the total population (Table 1).

Karlowski et al. also formed a group of "blinded" subjects, apparently from those who guessed incorrectly and those who made no guess, but the selection criteria for the "blinded" group were not explicitly described. In the "blinded" subjects there were no differ- 
TABLE 3. Therapeutic tablets: Guessing the treatment

\begin{tabular}{|c|c|c|c|c|}
\hline \multirow[b]{2}{*}{ Actual drug } & \multicolumn{2}{|c|}{ Answer } & \multirow{2}{*}{$\begin{array}{l}\text { Did not } \\
\text { guess }\end{array}$} & \multirow{2}{*}{$\begin{array}{c}\text { Total } \\
\text { subject }\end{array}$} \\
\hline & Placebo & Vitamin C & & \\
\hline \multirow{2}{*}{$\begin{array}{l}\text { Placebo } \\
\text { Vitamin C }\end{array}$} & 12 & $10(16 \%)^{\circ}$ & 40 & 62 \\
\hline & $\frac{11(16 \%)^{\alpha}}{x^{2}=1.2}$ & 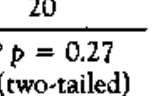 & 39 & \\
\hline
\end{tabular}

Subjects divided into groups on the basis of "guessing" and "knowing":

\begin{tabular}{|c|c|c|c|c|}
\hline \multirow[b]{2}{*}{ Actual drug } & \multicolumn{2}{|c|}{ "Gutessing" } & \multicolumn{2}{|c|}{ "Knowing" } \\
\hline & Placelbo & Vitamin $\mathrm{C}$ & Placebo & Vitamin $\mathbf{C}$ \\
\hline Placebo & $10^{x}$ & 10 & 2 & $\frac{\overrightarrow{9}}{9}$ \\
\hline Vitamin C & 11 & $11^{4}$ & - & 9 \\
\hline
\end{tabular}

${ }^{a}$ Percentage of subjects receiving the actual drug,

${ }^{b} \chi^{2}$ test with Yates' correction, Karlowski et al. did not use Yates' correction in analyzing the answers as to the therapeutic tablets. Karlowski et al gave $\chi^{2}=1.8$ [15], but the correct $\chi 2$ value is 1.90 without Yates' correction, and the reason for the slight discrepancy is not obvious. In the case of the prophylactic tablets Karlowski et al. did use Yates' correction (cf. Table 2).

${ }^{c}$ Correct guesses have been estimated from the number of wrong answers.

ences among the four treatment groups (Table 4). This led Karlowski et al. [15] and Chalmers [16] to infer that it was "knowing the treatment", i.e., the placebo effect, that caused the large differences in the "unblinded" subjects (Table 4) and the moderate differences in the whole study population (Table 1).

\section{Problems with the "Placebo Explanation"}

There are two questions relevant to Karlowski's and Chalmers's "placebo explanation." First, is the "placebo explanation" consistent with the observed results? Second, is there evidence that identification of the tablets actually resulted from tasting?

As regards the first question, the results (Tables 1 and 4) are not consistent with the "placebo explanation." In the study there were some 11 subjects who "really knew" their therapeutic tablets and some 56 subjects who "really knew" their prophylactic tablets (Tables 2 and 3). Thus, assuming that the results are caused by the placebo effect, we should expect that the prophylactic tablets would show much greater effect than the therapeutic tablets. However, prophylactic tablets were $34 \%$ less effective in all study subjects (0.485/0.735; Table 1) and 75\% less effective in "unblinded" subjects. $(0.75 / 3.05$; Table 4$)$ than the therapeutic tablets. The greater benefit from the therapeutic tablets is inconsistent with the "placebo explanation," since there is statistically no valid evidence that any subjects really knew the therapeutic tablets $(p=0.27)$, and only a few subjects, at most, did know (8\%).

Moreover, the selection criteria for the "unblinded" group were not explicitly described, although one may assume that it was composed of subjects who gave a correct answer to the query about both the therapeutic and prophylactic tablets. Neither was the number of subjects in the "unblinded" group revealed [15]. There were 52 cold episodes among the "unblinded" group (Table 4), and on average there were 1.3 colds per subject in the study [15]. Thus we may infer that there were some 40 subjects in the "unblinded" group. However, there were only some 11 subjects who "really knew" the therapeutic tablets in the entire study population (Table 3). If the placebo effect in these 11 subjects was responsible for the average of 3.05 days in the shortening of episodes by the therapeutic tablets
TABLE 4. Karlowski's subgroup analysis: Duration of cold episodes (in days) in "unblinded" and "blinded" groups"

\begin{tabular}{|c|c|c|c|}
\hline \multirow[b]{2}{*}{ Prophylactic } & \multicolumn{2}{|c|}{ Therapeutic } & \multirow{2}{*}{$\begin{array}{c}\text { Difference } \\
\text { (days) }\end{array}$} \\
\hline & Placebo & Vitamin C & \\
\hline \multicolumn{4}{|c|}{ "Unblinded" subjects } \\
\hline Placebo & $\begin{array}{c}8.6 \\
(16) \\
\# 0\end{array}$ & $\begin{array}{r}4.7 \\
(15) \\
\# 1\end{array}$ & -3.9 \\
\hline Vitamin $\mathrm{C}$ & $\begin{array}{l}7.0 \\
(8) \\
\# 2\end{array}$ & $\begin{array}{c}4.8 \\
(13) \\
\# 3\end{array}$ & -2.2 \\
\hline Difference (days) & -1.6 & +0.1 & -3.8 \\
\hline \multicolumn{4}{|c|}{ "Blinded" subjects } \\
\hline Placebo & $\begin{array}{r}6.3 \\
(30)\end{array}$ & $\begin{array}{r}6.7 \\
(18)\end{array}$ & +0.4 \\
\hline Vitamin $\mathrm{C}$ & $\begin{array}{r}6.4 \\
(14) \\
\end{array}$ & $\begin{array}{r}6.5 \\
(30) \\
\end{array}$ & +0.1 \\
\hline Difference (days) & +0.1 & -0.2 & +0.2 \\
\hline \multicolumn{4}{|c|}{$\begin{array}{l}\text { Difference between the "unblinded" and } \\
\text { "blinded" subgroups }\end{array}$} \\
\hline $\begin{array}{l}\text { Placebo } \\
\text { Vitamin C }\end{array}$ & $\begin{array}{l}+2.3 \\
+0.6\end{array}$ & $\begin{array}{l}-2.0 \\
-1.7\end{array}$ & \\
\hline
\end{tabular}

${ }^{a}$ The data for the "blinded" and "unblinded" subjects are from [15,16,25]. The outcome is the mean duration of episodes in days. The number of colds in each group is shown in parentheses and the number of the study group is marked below the mean duration of cold episodes.

in the entire "unblinded" group (Table 4), the "mean placebo effect" should be some 10 days among the 11 subjects who genuinely knew the therapeutic tablets. This provides a second reason why the "placebo explanation" leads to untenable logical consequences.

As regards the "placebo explanation" of Karlowski's results, it is not even sufficient to assume that realizing that one had been given ascorbic acid caused a decrease in the duration of symptoms. In fact, one must assume that the realization that one had been given lactose caused an even stronger psychological effect (Table 4). The colds were much longer in group 0 (double-lactose) of the "unblinded" subjects (8.6 days) when compared to the "blinded" (6.3 days). Thus, Karlowski et al. should more properly have discussed the "antiplacebo effect" of lactose as the major explanation of their results, since the "maximum effect" of lactose tablets was greater than the "maximum effect" of ascorbic acid tablets (2.3 days and -1.7 days, respectively; Table 4).

Furthermore, there is a problem with the division of subjects into the two categories of "blinded" and "unblinded" as it was done by Karlowski et al. These two groups contained $144(=92+52)$ cold episodes (Table 4), whereas there were 249 episodes among all subjects (Table 1). Thus there is a group of missing persons with a total of 105 cold episodes (Table 5); in other words, nearly half of all observed episodes are missing from Karlowski's subgroup analysis. In the missing group the mean duration of colds was 7.2 days in group 0 (double-placebo) and 5.8 days in group 3 (double-vitamin C). Thus, the therapeutic effect of the largest vitamin $\mathrm{C}$ dose $(6 \mathrm{~g} /$ day $)$ was greater in the missing group $(-1.4$ days; Table 5$)$ than in the whole study population (-1.22 days; Table 1$)$. It is not clear what Karlowski's explanation for the missing group was, and why it was not shown along with the data for the two other subgroups. 
TABLE 5. Colds missing from Karlowski's subgroup analysis: Duration of cold episodes (in days) in the missing group"

\begin{tabular}{|c|c|c|c|}
\hline \multirow[b]{2}{*}{ Prophylactic } & \multicolumn{2}{|c|}{ Therapeutic } & \multirow{2}{*}{$\begin{array}{c}\text { Difference } \\
\text { (days) }\end{array}$} \\
\hline & Placebo & Vitamin $\mathbf{C}$ & \\
\hline Placebo & $\begin{array}{c}7.2 \\
(19) \\
\# 0\end{array}$ & $\begin{array}{c}7.4 \\
(23) \\
\# 1\end{array}$ & +0.2 \\
\hline Vitamin C & $\begin{array}{c}6.8 \\
(30) \\
\# 2\end{array}$ & $\begin{array}{c}5.8 \\
(33) \\
\# 3\end{array}$ & -1.0 \\
\hline Difference (days): & -0.4 & -1.6 & -1.4 \\
\hline
\end{tabular}

${ }^{a}$ The data were calculated from the number and the mean duration of cold episodes in the "unblinded" and "blinded" groups (Table 4) and all subjects (Table 1). The outcome is the mean duration of episodes in days. The number of colds in each group is shown in parentheses and the number of the study group is marked below the mean duration of cold episodes.

As regards the second question, whether the tablets were identified by taste, the distribution of subjects who genuinely knew their therapeutic tablet (Table 3) is not consistent with the suggestion that tablets were identified by taste. If a subject found the tablet acidic he or she could not infer that the tablet contained ascorbic acid and not, for example, citric acid, which has been used in several other studies as a placebo [21-24]. By contrast, if a subject found the tablet sweet, he or she could infer that the tablet was not made of ascorbic acid or sodium ascorbate. Thus, in Karlowski's study the subjects could infer by taste that they were receiving placebo but not that they were receiving vitamin C. In the case of the therapeutic tablets the distribution of "genuinely knowing" subjects is, however, the opposite (Table 3). Thus the data do not support the notion that the therapeutic tablets were identified by taste. Neither do Karlowski et al. provide any explicit data from their questionnaire indicating that the identification of the therapeutic tablets would have been by taste $[15,16,25]$.

In the case of the prophylactic tablets the distribution of data is not quite inconsistent with tasting as one important source of information (Table 2). Since the study lasted for 9 months and the subjects took two prophylactic tablets three times per day, it seems quite obvious that several subjects tasted their prophylactic tablets during such a lengthy trial. In a parallel study report [25] the Karlowski group provided direct data on the tasting of prophylactic tablets as revealed by the questionnaire, but this paper was not referred to in the original JAMA report [15] or in Chalmers's review [16]. It can be estimated that of the 76 among the 190 study subjects who tasted the prophylactic tablets [25] only 60\% (46/76) "really knew" the correct tablet, consistent with the problems of inference from taste as noted above. From Karlowski's data it can also be calculated that $18 \%(10 / 56)$ of the subjects that "really knew" the prophylactic tablet had not tasted the tablets, indicating that there were other ways of identifying the type of prophylactic tablet [25]. No data were revealed about tasting the therapeutic tablets [25].

Finally, the criteria used for selecting subjects for the "blinded" and "unblinded" groups do not seem logical. As the authors wanted to test the hypothesis that "believing" one was given vitamin $\mathrm{C}$ or placebo could explain the results [15], they should not have separated the subjects with "incorrect answers" from those with "correct answers." The psychological effects should be identical when the subject believes in his or her answer, irrespective of whether the answer is true or false. Thus, Karlowski's separation of subjects with incorrect and correct answers into different subgroups appears questionable, as the purpose was to analyze the role of psychological effects specifically.

Thus, Karlowski's [15] and Chalmers's [16] "placebo explanation" is based on insufficient consideration of the consistency of the "placebo explanation" with the actual data from their own study. The greater therapeutic effect from the therapeutic tablets, which were not "known" to the subjects, is a strong argument against the placebo effect as the major explanation for the reported findings of the Karlowski study.

\section{AN ALTERNATIVE EXPLANATION OF THE BIAS IN "KNOWING": INFERENCE FROM THE SUBJECTIVE OBSERVATION}

There has been an enduring popular belief that vitamin $\mathrm{C}$ supplements alleviate the symptoms of the common cold, making it possible that several subjects inferred the vitamin $C$ treatment from the subjective feeling that the cold symptoms were mild. Similarly, the feeling that the symptoms were prolonged may have led a subject to infer that vitamin $\mathrm{C}$ was not being given, but rather placebo. The proposed explanation appears to explain the large bias in the distribution of subjects who "really knew" their therapeutic tablets (Table 3), since the subjective observation that symptoms are milder than usual may lead to the inference that the "active" drug has been given, whereas if there is no difference compared to previous colds one cannot confidently infer placebo, since the "active" drug could simply be ineffective.

In some studies [20-24] the difference in the duration of cold episodes between the placebo and vitamin $\mathrm{C}$ groups has been so great (30-70\% decrease with the vitamin) that it would be no surprise if vitamin $\mathrm{C}$ tablets could be correctly identified by some persons on the basis of subjective observation. Furthermore, when Asfora initiated a double-blind study to test the effects of $6 \mathrm{~g} /$ day of vitamin $\mathrm{C}$ on the common cold, subjects receiving the vitamin could be identified by their clinical progress [26]. With such data it appears unreasonable to assume that tasting was the only possible means to infer the contents of tablets in the Karlowski study.

In fact, the "knowledge inferred from the subjective observation" explanation is also directly supported by the data from the Karlowski study. Among subjects who had not tasted their prophylactic placebo tablets, those who had colds during the study tended to suspect that they were being given placebo, whereas those who did not have colds tended to suspect they were being given vitamin $C(p<0.05)$ [25]. A similar kind of inference can apparently be made from the duration of colds, but this was not considered by Karlowski et al. $[15,25]$. The alternative explanation is briefly mentioned but not properly analyzed in the JAMA report [15] and in the parallel study report [25], the "placebo explanation" being strongly favored in both papers. However, the alternative explanation is not mentioned at all in Chalmers's review [16].

Evidently the only logical possibility of using the "placebo explanation" is in explaining the difference between the prophylactic and therapeutic vitamin $\mathrm{C}$, since the former were correctly identified by many subjects but the latter only by a few. Since the prophylactic tables were less effective, one should assume that there was a small "antiplacebo" effect induced by prophylactic vitamin $\mathrm{C}$ tablets to explain the smaller benefit compared to the therapeutic tablets (Table 1). Nevertheless, statistical variation or a true physiological dif- 
ference between the two methods of supplementation would seem more reasonable explanations of this rather small difference.

\section{CONCLUSIONS}

The division of subjects into subgroups according to guessing the treatment, as was done in Karlowski's study, may easily result in misleading conclusions. For example, if penicillin is given to patients with bacterial infections the treatment may be beneficial for certain patients and ineffective for the rest. If we exclude from the analysis patients who, because of the subjective feeling of benefit, correctly answer a query after the study as to the tablets administered ("unblinded" subjects), we could end up with a group of patients infected with penicillin-resistant bacteria ("blinded" subjects). An analysis of the "blinded" subgroup of patients would lead to an entirely false impression of the usefulness of penicillin in patients infected with penicillin-sensitive bacteria. Thus, one should be very cautious, as Karlowski et al. were not, when dividing subjects into subgroups on the basis of variables that may be associated with a possibly real effect and guessing the treatment is obviously one of such variables. Obviously, the validity of the placebo should be examined before the study [23], and not after the completion of the study as was done by Karlowski et al.

The rejection of Karlowski's [15] and Chalmers's [16] "placebo explanation" is important since it validates the use of Karlowski's results in the quantitative estimation of the effects of vitamin C. Karlowski's results are important in three particular respects.

First, the comparison of the therapeutic and prophylactic methods of supplementation in the same study provides an estimate of their relative effects. Essentially all of the placebo controlled studies have used prophylactic supplementation [20-23], and it is an important question to what extent their results can be used as estimates of the benefit of therapeutic supplementation. From Karlowski's results it appears that with a fixed dose, a proper therapeutic supplementation can yield approximately as great a benefit as prophylactic supplementation (Table 1). Another therapeutic study carried out by Anderson et al. using 1-1.5 g/day of vitamin $\mathrm{C}$ for 5 days during cold episodes found a 25\% decrease in "days confined indoors" [24]. In a prophylactic study by Anderson et al. [23] with $1 \mathrm{~g}$ of vitamin $\mathrm{C}$ per day, given regularly ( $3 \mathrm{~g}$ /day extra during colds), the decrease in "days confined indoors" per episode was $21 \%$, which matches quite well with the results from the therapeutic study by the same group. Thus, Karlowski's study and Anderson's two studies suggest that the regular supplementation studies may be used to estimate the benefits from appropriate therapeutic vitamin $\mathrm{C}$ supplementation.

Second, Karlowski's results indicate that there is linear dose dependency even with high intakes of up to $6 \mathrm{~g} /$ day (Table 1), and it appears possible that still higher doses might produce even greater effects. The largest dose ( $6 \mathrm{~g} /$ day $)$ decreased the duration of colds by $17 \%$ and linear extrapolation suggests that $35 \mathrm{~g} /$ day would totally suppress common cold symptoms. Even though such a crude extrapolation must be regarded with great caution, it is noteworthy that Cathcart has suggested that the optimum dose of vitamin $\mathrm{C}$ in the treatment of the common cold would be over $30 \mathrm{~g} /$ day [7], quite consistent with this extrapolation. Thus, it seems probable that the vitamin $C$ doses used in the common cold studies ( $\leq 6 \mathrm{~g} / \mathrm{day}$; $[15,20-26])$ have not been large enough to reveal the maximum effects of vitamin $\mathrm{C}$ supplementation.

Third, the observed effect is quite small in Karlowski's study when considering the fairly large doses used. In several other studies smaller doses have produced greater effects [20-24]. One possible explanation for the rather small benefit is the character of the subjects used. Anderson et al. $[23,24]$ found that vitamin C supplementation was much more beneficial for subjects with a low daily intake of fruit juices (a major source of vitamin C). In their first study Anderson et al. [23] found that vitamin C (1-4 g/day) decreased the "days confined to house" per person by $48 \%$ in subjects with a low intake of fruit juices ( $<4 \mathrm{oz} /$ day), but only by $22 \%$ in subjects with a higher intake of fruit juices. It seems probable that the medically aware employees of the NIH have on average a much healthier diet than the general population and, for example, eat more fruits and fruit juices. Thus, Karlowski's study with employees of the NIH may underestimate the potential benefits of similar vitamin $\mathrm{C}$ doses for subjects with a diet more typical of the general population or for subjects with a decidedly poor diet.

Karlowski et al. considered that the effect, even if real, is in any case clinically insignificant, and concluded that "it does not seem worthwhile to take two capsules or tablets three times a day for the rest of one's life to achieve such a small and equivocal benefit" [15]. However, in concluding this they missed several important findings in their own study, which are discussed above. First, they could have noted that three times a day during a cold episode is much more feasible and much less costly than "three times a day for the rest of one's life," and their own results suggest the benefit from therapeutic supplementation is at least as great as from regular supplementation. Second, as there was a linear dose dependency in their own results they could have noted that therapeutic doses larger than $6 \mathrm{~g} /$ day would probably have decreased the duration of episodes by over $17 \%$. Third, they cited Anderson's first paper [23], reporting that vitamin C supplementation is much more beneficial for subjects with low fruit juice intake, and consequently could have noted that their own subjects were probably not the kinds of subjects who would derive the greatest benefit from vitamin $\mathrm{C}$ supplementation.

On the basis of published placebo controlled studies it is obvious that vitamin $\mathrm{C}$ supplementation decreases the duration and severity of common cold episodes [11,15,20-26]. However, there are numerous open questions as regards the optimum dose, the best methods of treatment, the maximum therapeutic effects, etc. It also appears likely that the effects of vitamin $\mathrm{C}$ supplementation vary greatly among different subgroups of people. For example, Anderson et al. found in two studies that vitamin $\mathrm{C}$ supplementation was more beneficial for subjects with low dietary vitamin $\mathrm{C}$ intake and for subjects who were in contact with young children $[23,24]$. They also found other differences between subgroups, but those were not as consistent. Thus, it would appear more relevant to ask which are the subgroups that would benefit most from vitamin $\mathrm{C}$ supplementation, rather than to ask whether a fixed numerical value found, for example, with employees of the NIH is great enough to validate regular vitamin $C$ supplementation for the general population.

It appears that an important reason preventing proper conclusions from the vitamin C-common cold studies has been the preconception that vitamin $\mathrm{C}$ cannot affect the common cold. In addition to Karlowski's analysis of their own results [15], the bias is apparent in Chalmers's concurrent review [16], in which data conflicting with original published results were used and the analysis of results was carried out improperly, rendering the assessment of the effect meaningless [22]. Anderson et al. [23] explicitly noted that when planning their first study they were skeptical that vitamin $\mathrm{C}$ could have any effects on the common cold, and therefore they tried to make as 
large and as careful a study as possible so that critics could not argue that a negative result might be due to the technical shortcomings of the study. Their placebo consisted of citric acid and in a pilot trial the placebo and ascorbic acid tablets could not be distinguished. The conclusion that vitamin $\mathrm{C}$ does have physiological effects on the common cold symptoms seemed inescapable [23]. Pauling, who enthusiastically proposed that vitamin $\mathrm{C}$ supplements could help against the common cold [9], complained that many of his critics had not read either his texts or the original reports and gave several detailed examples to support his case [11]. The obvious shortcomings in the Karlowski and Chalmers "placebo explanation" give further support to Pauling's allegation that many people have not analyzed the available data thoroughly and objectively, although they maintain strongly held views.

The nutritional recommendation for vitamin C, $60 \mathrm{mg} / \mathrm{day}$ [27], is not based on clinical or epidemiological studies suggesting that such a dose would be the best for health in the long term; rather, the only criterion is that such a dose prevents overt scurvy with an ample safety margin [11,27-33]. Vitamin $C$ participates in a number of enzymatic and nonenzymatic reactions [20,32-35], and consequently it is quite possible that the physiological effects of the vitamin are not limited to the prevention of overt scurvy. As regards the effects of vitamin $\mathrm{C}$ on the immune system in particular it is noteworthy that very high concentrations of vitamin $\mathrm{C}$ are found in phagocytes and lymphocytes [36,37]. It appears that vitamin $\mathrm{C}$ may provide protection against reactive oxygen species produced in an infection; also, it may increase the proliferative responses of $\mathrm{T}$ lymphocytes and the production of interferon (for references see [20,22]). Published intervention studies [15,20-26] suggest that it would be worthwhile to carry out further controlled studies to assess the effects of large therapeutic vitamin $\mathrm{C}$ doses on the symptoms of the common cold.

The author is grateful to Dr Pekka Louhiala for his critical reading of the manuscript. This work was supported by the Academy of Finland.

\section{References}

1. Ruskin SL. Calcium cevitamate in the treatment of acute rhinitis. Ann Otol Rhinol Laryngol 1938; 47: 502-511.

2. Markwell NW. Vitamin C in the prevention of colds. Med J Aust 1947; 34: 777-778.

3. Woolstone AS. Treatment of the common cold. (Letter.) Br Med J 1954; $2: 1290$

4. Regnier E. The administration of large doses of ascorbic acid in the prevention and treatment of the common cold. II. Rev Allergy 1968; 22: 948-956.

5. Luberoff BJ. Symptomectomy with vitamin C. A chat with Robert Cathcart. Chemtech 1978; 8; 76-86.

6. Bee DM. The vitamin C controversy. (Letter.) Postgrad Med 1980; 67(2): 64.

7. Cathcart RF. Vitamin C, titrating to bowel tolerance, anascorbemia, and acute induced scurvy. Med Hypotheses 1981; 7: 1359-1376.

8. Gotzsche AL. Pernasal vitamin C and the common cold. (Letter.) Lancet $1989 ; 2: 1039$.

9. Pauling L. Vitamin C and the Common Cold. San Francisco: Freeman; 1970. (Reprinted in 1976 as Vitamin C, Common Cold, and the Flu.)
10. Stone, I. The Healing Factor: Vitamin C against Disease. New York: Grosset and Dunlap; 1972.

11. Pauling L. How to Live Longer and Feel Better. New York: Freeman; 1986.

12. Gwaltney JM: The common cold. In: Mandell GL, Bennett JE, Dolin R, eds. Principles and Practice of Infectious Diseases, 4th Ed. New York: Churchill Livingstone; 1995: 561-566.

13. Rivers JM. Safety of high-level vitamin C ingestion. Ann NY Acad Sci 1987; 498: 445-454.

14. Bendich A. Safety issues regarding the use of vitamin supplements. Ann NY Acad Sci 1992; 669: 300-312.

15. Karlowski TR, Chalmers TC, Frenkel LD, Kapikian AZ, Lewis TL, Lynch JM. Ascorbic acid for the common cold. A prophylactic and therapeutic trial. JAMA 1975; 231: 1038-1042.

16. Chalmers TC. Effects of ascorbic acid on the common cold. An evaluation of the evidence. Am J Med 1975; 58: 532-536.

17. Dykes MHM, Meier P. Ascorbic acid and the common cold. Evaluation of its efficacy and toxicity. JAMA 1975; 231: 1073-1079.

18. Coulehan J. Ascorbic acid and the common cold. Reviewing the evidence. Postgrad Med 1979; 66(3): 153-160.

19. Sperber SJ, Hayden FG. Chemotherapy of rhinovirus colds. Antimicrob Agents Chemother 1988; 32: 409-419.

20. Hemilä H. Vitamin C and the common cold. Br J Nutr 1992; 67 : 3-16.

21. Hemilä $H$. Does vitamin $C$ alleviate the symptoms of the common cold? A review of current evidence. Scand J Infect Dis 1994; 26: $1-6$

22. Hemilä H, Herman ZS. Vitamin C and the common cold. A retrospective analysis of Chalmers' review. J Am Coll Nutr 1995; 14: 116-123.

23. Anderson TW, Reid DB, Beaton GH. Vitamin C and the common cold: A double-blind trial. Can Med Assoc J 1972; 107:503-508.

24. Anderson TW, Beaton GH, Corey PN, Spero L. Winter illness and vitamin C: The effect of relatively low doses. Can Med Assoc J 1975; 112 823-826.

25. Lewis TL, Karlowski TR, Kapikian AZ, Lynch JM, Shaffer GW, George DA. A controlled clinical trial of ascorbic acid for the common cold. Ann NY Acad Sci 1975; 258: 505-512.

26. Asfora J. Vitamin C in high doses in the treatment of the common cold. Int J Vitam Nutr Res 1977; Suppl. 16: 219-234.

27. National Research Council. Recommended Dietary Allowances, 10th Ed. Washington, D.C.: National Academy Press; 1989; 115-124.

28. Pauling L. Are recommended daily allowances for vitamin $\mathrm{C}$ adequate? Proc Natl Acad Sci USA 1974; 71: 4442-4446.

29. Hughes RE. Recommended daily amounts and biochemical roles. In: Counsell JN, Hornig DH, eds. Vitamin C. London: Applied Science Publishers; 1981: 75-86.

30. Hemilä H. Nutritional need versus optimal intake. Med Hypotheses 1984; 14: 135-139.

3L Hemilä H. A re-evaluation of nutritional goals: not just deficiency counts. Med Hypotheses 1986; 20: 17-27.

32. Levine M. New concepts in the biology and biochemistry of ascorbic acid. N Engl J Med 1986; 314: 892-902.

33. Ginter E. Ascorbic acid in cholesterol metabolism and in detoxification of xenobiotic substances: The problem of optimum vitamin $\mathrm{C}$ intake. Nutrition 1989; 5: 369-374.

34. Englard S, Seifter S. The biochemical functions of ascorbic acid. Annu Rev Nutr 1986; 6: 365-406.

35. Padh H. Cellular functions of ascorbic acid. Biochem Cell Biol 1990 ; 68: 1166-1173.

36. Bergsten P, Amitai G, Kehrl J, Dhariwal KR, Klein HG, Levine M Millimolar concentrations of ascorbic acid in purified human mononuclear leukocytes. J Biol Chem 1990; 265: 2584-2587.

37. Washko PW, Wang Y, Levine M. Ascorbic acid recycling in human neutrophils. J Biol Chem 1993; 268: 15531-15535. 